\title{
Disseminated Abdomino-Throracic Hydatidosis Presenting as Mediastinal Syndrome
}

\author{
Amol Andhale ${ }^{1}$, Sourya Acharya ${ }^{2}$, Kanchan Devde ${ }^{3}$, Samarth Shukla ${ }^{4}$ \\ 1,2 Department of Medicine, Datta Meghe Institute of Medical Sciences (Deemed to Be University), \\ Sawangi Meghe, Wardha, Maharashtra, India, ${ }^{3}$ Department of Medicine, MGM Medical College, \\ Aurangabad, Maharashtra, India, ${ }^{4}$ Department of Pathology, Datta Meghe Institute of Medical \\ Sciences (Deemed to Be University), Sawangi Meghe, Wardha, Maharashtra, India.
}

\section{INTRODUCTION}

Hydatid disease, one of the most geographically widespread zoonoses is caused by tape worm Echinococcus granulosus. It is endemic in areas with increased cattle grazing with substantial disease burden. We report a case of a male who presented with symptoms and signs of mediastinal compression and was diagnosed to have disseminated hydatid disease.

\section{PRESENTATION OF CASE}

A 45-year-old male presented with complaint of breathlessness, (NYHA -New York Heart Association- grade III), since 3 months which progressed to NYHA grade IV since 8 days and abdominal pain since 2 months. There was a history of orthopnoea and palpitations.

\section{On Examination}

Pulse - 118 / min, regular, respiratory rate 24 / min, temperature - afebrile, blood pressure 90 / $40 \mathrm{mmHg}$, Jugular vein pressure (JVP) was raised and non - pulsatile. CVS - S1 loud no murmur, Respiratory system - Air entry was completely absent in right hemithorax. Abdominal examination - abdomen distended predominantly in right hypochondrium and lumbar area.

\section{Investigations}

$\mathrm{CBC}-\mathrm{Hb}-10.8$ gram \%, TLC - 3,500 / mm3. Liver function test and renal function tests were within normal limits. CT Abdomen revealed - Large hypodense mass lesion involving entire lobe of the liver, extending interiorly into right hypochondrium-iliac region with intraperitoneal component with superior extension in right hemithorax with left ward mediastinal shift, showing enhancing peripheral wall and internal spoke wheel pattern of septal enhancement suggestive of disseminated abdominothoracic hydatidosis. (Fig. 1)

\author{
Corresponding Author: \\ Dr. Sourya Acharya, \\ Professor, \\ Department of Medicine, \\ Datta Meghe Institute of \\ Medical Sciences (Deemed to Be \\ University), Sawangi Meghe, \\ Wardha, Maharashtra, India \\ E-mail: souryaacharya74@gmail.com
}

\section{DOI: $10.14260 / j e m d s / 2021 / 373$}

How to Cite This Article:

Andhale A, Acharya S, Devde $K$, et al. Disseminated abdomino-throracic hydatidosis presenting as mediastinal syndrome. J Evolution Med Dent Sci 2021;10(23):1807-1808, DOI: 10.14260/jemds/2021/373

Submission 15-04-2020,

Peer Review 08-04-2021,

Acceptance 15-04-2021,

Published 07-06-2021.

Copyright (c) 2021 JEMDS. This is an open access article distributed under Creative Commons Attribution License [Attribution 4.0 International (CC BY 4.0)] 


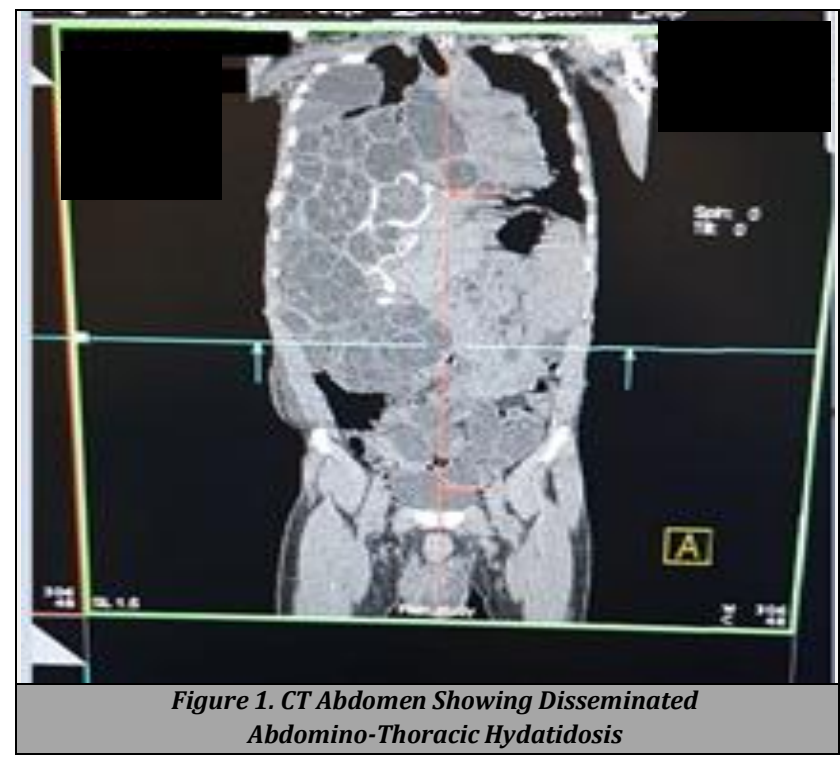

\section{DISCUSSION}

Hydatid disease is caused by ingestion of the cestode larva called echinococcus. echinococcus can only infect humans when they have a close contact with animals. echinococcus infection leads to the development of cysts in different organs, particularly in the liver followed by lungs. ${ }^{1}$ Primary dissemination is rare and accounts for 2 percent of intraabdominal hydatidosis.

Our patient had disseminated abdomino thoracic hydatid disease involving entire liver lobe, extending interiorly into right hypochondrium, iliac region with intraperitoneal component with superior extension in right hemithorax with left ward mediastinal shift. The raised non pulsatile JVP was due to compression of superior vena cava. Diagnosis was aided by ultrasound or CT scan. ${ }^{1}$ Surgery is indicated for localized, complicated, superficial or multiseptated cysts whereas PAIR (puncture, aspiration, injection, re aspiration) is useful for simple cysts, poor surgical candidates, or pregnancy. ${ }^{2}$ However, both forms require peri-interventional benzimidazole therapy. ${ }^{2}$ Albendazole with / without praziquantel is used to treat disseminated disease. ${ }^{2}$ Surgery is the mainstay of treatment.

Hydatid cysts can be treated by surgical or medical intervention. Surgical resection is the key for the treatment of lung and liver hydatid cysts and is beneficial for patients where cysts cause compression due to their large size. ${ }^{3}$ However, in patients with primary liver or lung cysts that are inoperable, medical therapy is required. Because of large distribution, the hydatid cyst was inoperable in our patient.

Financial or other competing interests: None.

Disclosure forms provided by the authors are available with the full text of this article at jemds.com.

\section{REFERENCES}

[1] Almalik A, Alsharidi A, Al-Sheef M, et al. Disseminated abdominal hydatidosis: a rare presentation of common infectious disease. Case Rep Infect Dis 2014;2014:164787.

[2] Brunetti E, Kern P, Vuitton DA, et al. Expert consensus for the diagnosis and treatment of cystic and alveolar echinococcosis in humans. Acta Trop 2010;114(1):1-16.

[3] Iqbal N, Hussain M, Idress R, et al. Disseminated hydatid cyst of liver and lung. BMJ Case Reports 2017. 